\title{
¿Hay un "impensado" en la relación entre periodismo y política?
}

Carlos 0ssandón B.

Doctor en Filosofía, graduado en la Universidad de Gante, Bélgica.Profesor Titular Instituto de la Comunicación e Imagen de la Universidad de Chile

cob2002@u.uchile.cl

Fruto de una larga investigación, y de una estadía de cuatro años en el ICEl, Antoine Faure defendió su tesis doctoral en la Universidad de Grenoble, Francia, el 8 de diciembre de 2014. Su título Des (-) órdenes periodísticos en una crisis revolucionaria. Crónicas del ser periodístico chileno durante la Unidad Popular (1970-1973). He aquí el comentario que realicé en aquella ocasión:

Sobre la base de una pesquisa extremadamente paciente y rigurosa, que exhibe una muy maciza y pertinente documentación que combina distintos tipos de fuentes, la presente Tesis levanta importantes interrogantes en el esfuerzo por revisar o problematizar las relaciones entre periodismo y política. ¿Qué significó ser "periodista” en los tiempos acelerados e intensos de la Unidad Popular en Chile? ¿Cómo operaron los media y más particularmente el periodismo en este período? ¿Es dable afirmar que en el subsuelo de la pugna ideológica operó un nivel tan o más determinante que este, y que se mantiene aun en la sombra? ¿Qué importancia conceder a unas prácticas o exterioridades en apariencia meramente instrumentales, nimias, neutras, en "grado cero" diría Barthes, por medio de las cuales se construyen unos mensajes que parecen ser los únicos importantes de atender, ya en ellos se comprometerían los factores más determinantes en el ámbito ideológico o político? ¿Hay en la prensa otro lugar para la política más allá de la muy activa participación que le cupo en el duro enfrentamiento de visiones de mundo que tuvo lugar durante la UP? Es sobre estos "impensados" de la actividad periodística que la presente Tesis justifica su esfuerzo: es esta zona de "sombra" lo que la investigación se propone esclarecer.

Para llevar a cabo su acometido, el trabajo revisa distintas visiones sobre la relación entre periodismo y política (por ejemplo, la teoría de la "dependencia" y el énfasis que 
se puso en las décadas del 60 y del 70 en el control monopólico de los medios), muestra las posibilidades y límites de los trabajos historiográficos referidos al período, así como las no insignificantes relaciones o juegos de validación política que se hacen entre las lecturas del pasado y las del presente. En el marco de unos discursos que operan no tan solo como "estados del arte" sino principalmente como "acontecimientos" históricos, no disociables por lo tanto de la trama que se busca analizar, el trabajo que analizamos se propone desarrollar una mirada específica sobre la prensa, que se apoya en el tiempo largo y en la "autonomía" relativa que ha conquistado su práctica y el sistema de comunicación moderno ya desde la segunda mitad del siglo XIX en Chile. Un sistema que si bien da siempre cuenta de fuerzas sociales y políticas distintas y en competencia, ya no es siempre mera superficie de proyección de dichas fuerzas. La investigación hace así una muy clara contribución al desarrollo de un "campo" cuya complejidad requiere del uso reflexivo de unas categorías o de unos mapas cognitivos que no están a la mano, que no son fáciles de dominar en la medida que no siempre coinciden con lugares comunes y que están lejos de haber agotado o llevado al límite sus posibilidades o rendimientos analíticos. El carácter construido de los artefactos periodísticos, la capacidad de la prensa de hacer circular "significaciones" propias, la apropiación que realiza de un habla que tiene sus singularidades y gracias a la cual fabrica-segmenta el "presente", son todas cuestiones que permiten pensar esta práctica ya no como un simple derivado de otras realidades más determinantes. Si he entendido bien, la mirada que se propone busca -en un plano general- no disociar materialidad y sentido, práctica y significación, destacando así -en un plano más específico- los elementos histórico-estructurales, institucionales, corporativos, laborales, tecnológicos y de validación social que están en la base del periodismo.

Teniendo en cuenta estas consideraciones, la presente investigación examina aquello que parece darse de suyo: las prácticas periodísticas, sus rutinas o sistemas de trabajo, el proceso de producción de las noticias, el saber-hacer invertido en él. En la descripción de estos singulares e históricos procesos de producción cotidiana de la información, o en la diferencia que ellos mantienen con otros modos de construcción de lo real, la Tesis asocia estas mediaciones con su rendimiento político. Me parece que es este un punto muy alto o central de la presente Tesis, y que supone, en la revaloración de estas mediaciones, importantes desplazamientos en los ámbitos ideológico y político. Estos desplazamientos, que representan no menores ajustes de cuentas, resituan o resignifican el conjunto de componentes que definen el periodismo moderno: no solo la división del trabajo que se realiza en las oficinas del periódico, también las visibilidades o exterioridades sígnicas 
que organizan las planas del periódico o la distribución de sus secciones. Sin dejar de atender también la dimensión profesional o gremial que tiene este ejercicio, así como los mecanismos de socialización, de enseñanza, de refuerzo o vigilancia de lo que se estima el "buen" periodismo. Más allá de la focalización exclusiva en "representaciones" o "contenidos", e incluso de la adscripción partidaria de los periódicos, es todo este subsuelo práctico, cotidiano, "normal", y que se arrastra mucho antes de los tres años de la UP, al que se le dota de una politicidad que la Tesis se encarga de resaltar. Es allí, en esas objetividades, tramposamente insípidas, donde se "domestica cotidianamente el tiempo de la actualidad" (p. 329), donde se organiza o toma forma el "mundo", nuestro presente. Aun cuando este proceso de normalización o disciplinamiento del tiempo no puede soslayar, menos todavía en los tiempos impetuosos de la UP, las diversas modalidades de vínculo o de directa participación de la prensa en la aguda lucha política que se dio en ese período, esta construcción o modelación ya no depende únicamente de estas relaciones o no es tan solo el simple reflejo de aquella lucha. Así se da la paradoja que la tantas veces mencionada "crisis" institucional o política no tendría, en los tiempos de la UP, un correlato en el subsuelo práctico de la prensa (las formas de fabricación de la noticia y la organización de las planas se mantuvieron en lo esencial inalterables), por más que ciertos análisis necesiten de dicha "crisis" para validar hoy un tipo de periodismo afín a la "transición", alejado del "conflicto" o de los "excesos".

La Tesis se apoya así, según mi modo de ver, en una ampliación de la esfera política. Ella no se reduce a aquellas formas, instituciones o prácticas (el Estado, el Parlamento, las elecciones) que suelen absorber esta esfera, abriéndose a otras gramáticas o principios de articulación, incluyendo técnicas de control del tiempo y de sus aceleraciones, formatos aparentemente anodinos, organizaciones perceptivas, formas de escritura o "pirámides invertidas". Unas prácticas, ciertamente no necesarias, ni tampoco simples "medios", que a su modo "significan", no siendo ajenas por lo tanto a la modelización del mundo, a la esquematización del presente, al apego a la "actualidad" y al rechazo de esa "inactualidad" que pareció seducir a Nietzsche.

La ampliación de la esfera política hace legítima entonces la pregunta sobre los modos de operar de las exterioridades o materialidades propias del trabajo periodístico en ese tiempo impetuoso que fue la UP. La Tesis, aun cuando pudo avanzar algo más en este terreno, hace interesantes aportes: destaca la discusión o politización que se dio en torno a la "objetividad" periodística, la revisión del "relato" periodístico liberal, las tensiones 
entre prácticas y contra prácticas periodísticas o, por citar un ejemplo relevante, que hace patente la relación entre la positividad de la forma y la política, la transgresión que hace El Mercurio de su propio relato metaperiodístico, al presentar una portada que dibuja una "cola" (práctica corriente durante la UP) que sin decir reconfigura o le da otro valor al espaciamiento periodístico.

Si bien como decíamos se pudo avanzar un poco más en este último terreno (en aquellas regularidades e irregularidades periodísticas que hacen visible en ellas, y no fuera de ellas, una particular denotación/connotación política), la Tesis -en un balance generalcombina bastante bien y con mucha propiedad y erudición los distintos componentes del escenario periodístico y político del período. Es en este escenario donde, a mi modo de ver, la investigación desarrolla una perspectiva original y específica sobre la relación básica entre periodismo y política. En este sentido, no parece ser su propósito esencial un relectura global de la UP como experiencia política, a pesar de la muy interesante problematización que se hace del "teleologismo" histórico.

Para concluir, digamos que la presente investigación enseña unos ribetes existenciales o personales que singularizan y potencian un trabajo que, según lo declara su autor, es más que un ejercicio universitario (p. 67). Lo que quizá Antoine Faure no sabe es que su comprometida inserción en la realidad chilena y en esa cercanía-lejanía que articula su investigación, el autor revela por doquier unas sorpresas, unas perturbaciones teoricopolíticas o unas rarezas culturales que son particularmente ricas para quienes nacimos y vivimos en esta finis terrae. Ellas me conmueven, las agradezco, y me están permitiendo entender un poco mejor nuestro a ratos inescrutable ethos. 